in vivo $32: 977-981(2018)$

doi:10.21873/invivo.11338

Review

\title{
Vitamin D in Cardiovascular Disease
}

\author{
ALKIPPI NITSA $^{1,2}$, MARINA TOUTOUZA ${ }^{2}$, NIKOLAOS MACHAIRAS ${ }^{1}$, \\ ANARGYROS MARIOLIS $^{3}$, ANASTASSIOS PHILIPPOU ${ }^{1}$ and MICHAEL KOUTSILIERIS ${ }^{1}$ \\ ${ }^{1}$ Department of Physiology, Medical School, National and Kapodistrian University of Athens, Athens, Greece; \\ ${ }^{2}$ Biochemistry \& Microbiology Laboratory, Hipokrateion Hospital, Athens, Greece; \\ ${ }^{3}$ Health Center, National Health System, Areopolis, Greece
}

\begin{abstract}
Cardiovascular disease is the prevalent cause of morbidity and mortality in the world, affecting many millions of individuals every year. Atherosclerosis, a chronic inflammatory condition that involves different cell types, several cytokines and adhesion molecules, is the underlying cause of cardiovascular disease. Vitamin D is known to control skeletal patho/physiology, regulating calcium and phosphorus and bone remodeling along with other calciumregulating hormones. However, several active metabolites of vitamin $D$ can exert both direct action, mainly via vitamin $D_{3}$ receptor trans-activation and indirect actions on several other tissues by an endocrine, autocrine and paracrine manners. With regard to cardiovascular disease, vitamin $D$ deficiency has been associated with activation of the proinflammatory mechanism, promoting atherogenesis. There are several large-scale clinical studies, as well as metaanalyses that support this finding. However, it is still unclear whether the plasma 25-hydroxyvitamin D level can be used as a biomarker for future cardiovascular disease. Herein we review the studies reporting a causative role for vitamin $D$ in cardiovascular disease.
\end{abstract}

Over the past few years, spectacular progress has been made in the fields of drug and biomarker discovery, as well as in understanding of the pathophysiological mechanisms of several diseases (e.g. cardiovascular and neurodegenerative

This article is freely accessible online.

Correspondence to: Michael Koutsilieris, MD, Ph.D, Department of Physiology, Medical School, National \& Kapodistrian University of Athens, Micras Asias 75, Goudi-Athens 115 27, Greece. E-mail: mkoutsil@med.uoa.gr

Key Words: Atherosclerosis, cardiovascular disease, matrix metalloproteinases, vitamin D, vitamin D receptor, review. diseases, and cancer). Interestingly, a growing body of research is now focusing on prevention, rather than the treatment of disease. Thus, the discovery of new biomarkers, especially for early stages of a disease, has become of particular interest in the context of early identification of disease that can lead to improved therapeutic efficacy and greater overall survival.

\section{Cardiovascular Disease and Atherosclerosis}

Cardiovascular disease (CVD) is the leading cause of morbidity and mortality worldwide. It is defined as a set of diseases and conditions that usually manifest as heart attacks and strokes. It was considered to be a disease of the Western world, but recent evidence points to the fact that populations of emerging and even low-income countries also suffer from it. In 2015, the World Health Organization (WHO) estimated that CVD accounted for more than 17.7 million deaths, representing a total $31 \%$ of global deaths (1).

The main condition underlying CVD is atherosclerosis. Atherosclerosis is nowadays not considered to be a lipid storage disease, but can be better termed as low-grade inflammation of the vascular wall. It is characterized by the deposition of lipids and the subsequent accumulation of Tcells and macrophages as a result of endothelial injury response (2). In these process, reactive oxygen species play a pivotal role as they can cause oxidation of lipids such as low-density lipoprotein (LDL) and polyunsaturated fatty acids that are deposited in the vascular wall, directly damage cellular components, and further promote inflammation by activating several pro-atherogenic transcriptional factors (3). Over the course of time, atherosclerotic lesions are formed, which through the action of several cytokines can rupture and lead to occlusion of the vascular lumen. Depending on the area of rupture, these can manifest as acute myocardial infractions or stroke or acute ischaemia of any nearby organ (4). 
Over the last few years, our understanding of atherosclerotic processes has vastly improved; however, there are still many mechanisms that have not been fully elucidated. It is evident that prevention and early detection of atherosclerotic plaques still remains a high priority. Towards this end, many biomarkers have been developed, with many being used in everyday clinical practice. Often these biomarkers have significant advantages and disadvantages and numerous clinical studies have been conducted in order to verify their use in clinical practice (5). Most biomarkers are cardiac muscle-related, but there is an increasing interest in novel biomarkers that can allow detection of CVD well before damage to cardiac muscle occurs (6).

\section{Vitamin D Biosynthesis and VDR Signaling}

Vitamin D is a group of secosteroids mainly responsible for enhancing the intestinal absorption of calcium and phosphate. The most important compounds in this group are vitamin $\mathrm{D}_{3}$ (cholecalciferol) and vitamin $\mathrm{D}_{2}$ (ergocalciferol). Cholecalciferol and ergocalciferol can be ingested from the diet as well as from various supplements (7). The human body is also capable of synthesizing vitamin $\mathrm{D}$, specifically cholecalciferol, in the skin from cholesterol when sun exposure is adequate. Although vitamin D is commonly called a vitamin, it is not actually an essential dietary vitamin in the strict sense as it can be synthesized in adequate amounts by most mammals exposed to sunlight. By definition, only substances that cannot be synthesized sufficiently by a living organism and can only be obtained through its diet can be classified as essential vitamins. Similarly to other compounds commonly called vitamins, vitamin D was discovered in an effort to find the dietary substance lacking in individuals in with rickets, the childhood form of osteomalacia (8). Similarly to other vitamins, in many parts of the world, vitamin D is added to staple foods, such as milk, to avoid disease due to its deficiency.

Synthesis from exposure to sunlight, as well as intake from the diet, generally contributes to the maintenance of adequate vitamin D concentrations in serum. Evidence indicates the synthesis of vitamin D from sun exposure is regulated by a negative feedback loop that prevents toxicity, but no recommendations have been issue on suggested exposure to sunlight for optimal vitamin D synthesis, due to uncertainty about the cancer risk from sunlight (9). The Dietary Reference Intake for vitamin D assumes no synthesis occurs and that all vitamin D intake is from food, although in practice such an occurrence is very rare (10). In the liver, cholecalciferol (vitamin $\mathrm{D}_{3}$ ) is converted to 25-hydroxycholecalciferol, or 25hydroxyvitamin $\mathrm{D}_{3},\left(25(\mathrm{OH}) \mathrm{D}_{3}\right)(11)$. Ergocalciferol (vitamin $\mathrm{D}_{2}$ ) is converted in the liver to 25-hydroxyergocalciferol, also known as 25-hydroxyvitamin $\mathrm{D}_{2}\left(25(\mathrm{OH}) \mathrm{D}_{2}\right)$. These are the two specific vitamin $\mathrm{D}$ metabolites that are measured in serum/plasma to determine a person's vitamin D status (12). Part of calcidiol is converted by the kidneys to calcitriol, the biologically active form of vitamin D (4). Calcitriol circulates as a hormone in the blood, regulating the concentration of calcium and phosphate in the bloodstream and promoting healthy growth and remodeling of bone. Calcitriol also affects neuromuscular and immune function (13). A plasma concentration above $50 \mathrm{nmol} / 1$ is the target level for dietary intake recommendations of vitamin $\mathrm{D}$ in several Western countries, using data of studies of optimal and suboptimal skeletal health (14).

Vitamin $\mathrm{D}_{3}$ is often considered a hormone rather than a vitamin because of the fact that the active vitamin $\mathrm{D}$ metabolite exerts its action through the vitamin D receptor (VDR) in cells. The VDR is an intracellular hormone receptor that specifically binds the biologically active form of vitamin $\mathrm{D}_{3}$, calcitriol. It subsequently interacts with specific response elements and induces response of various genes with a plethora of physiological effects (15). VDR is almost ubiquitously expressed in the nucleus of most cells. Circulating calcitriol diffuses through the cell membrane and nuclear membrane and binds to the VDR, causing a conformational change in the receptor, leading to its heterodimerization with retinoic acid Xreceptor (RXR). It can also form a heterodimer with other members of the steroid receptor gene family (16). This transactivation of VDR results in the expression or repression of several other genes. It has been estimated that calcitriol regulates more than 200 genes, directly or indirectly, thereby influencing a wide variety of physiological processes (15). Interestingly, VDR-DNA binding can help facilitate the targeting of genes that can be further modified by calcitriol. However, there are many cases where the changes in gene expression are not mediated directly by the VDR but through many different co-regulatory elements (17). These complexes usually contain one VDR regulatory component and have significant enzymatic activity (16).

\section{Vitamin D and Cardiovascular Physiology}

Several cells and tissues of the cardiovascular system abundantly express either calcitriol or VDR. These include cardiomyocytes, and vascular and endothelial cells (18). VDR activation in endothelial cells can regulate their development through modulation of elements in the vascular endothelial growth factor (VEGF) promoter (19). Furthermore, higher VDR expression has been observed in stressed endothelial cells (20) and increased concentrations of calcitriol have been shown to decrease cytokine and adhesion molecule expression (21).

In cardiomyocytes, calcitriol was found to regulated cell maturity and differentiation (22). In addition, animal models lacking VDR expression demonstrated increased ventricular mass and higher levels of matrix metalloproteases (MMPs) and 


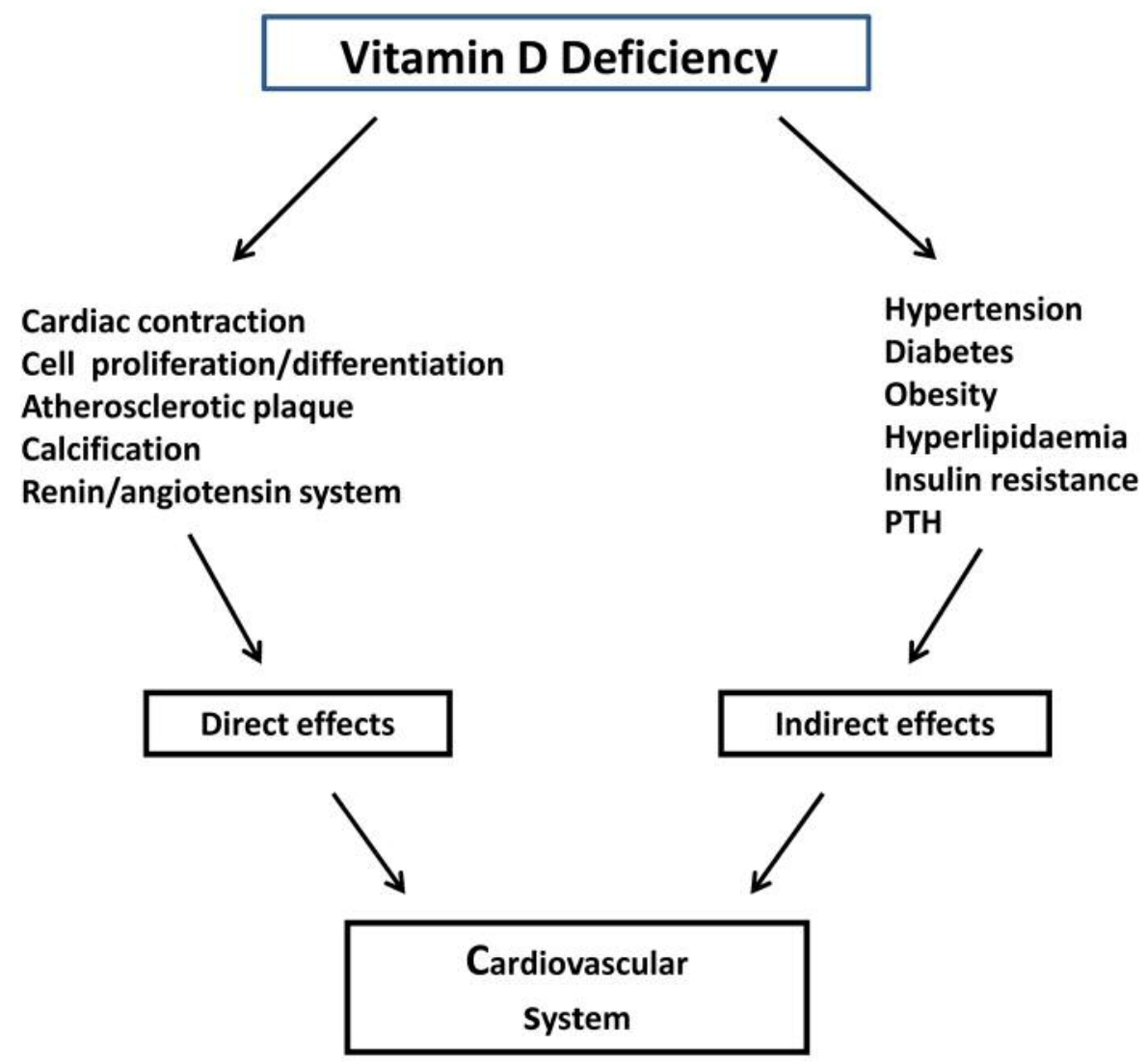

Figure 1. Potential associations between vitamin D deficiency and cardiovascular disorders. Vitamin D deficiency affects the cardiovascular system both directly and indirectly through the multiple roles that it plays in various conditions and pathologies associated with cardiovascular system (see text for details). PTH: Parathyroid hormone.

atrial natriuretic peptide (ANP) (23). As well as this, in rats, vitamin D-deficient diet led to a higher systolic pressure and lower calcium concentration. Interestingly supplementation of vitamin D analogs, led to reversal of these effects (24).

There has also been evidence that vitamin $\mathrm{D}$ can regulate matrix homeostasis. Such actions may prove to be critical in inflammatory and aneurismal diseases, where matrix destabilization is significant (25). There are several studies that suggest that calcitriol can suppress several MMPs (26). Furthermore, in VDR knockout mice, the expression of tissue inhibitor of MMP1 and tissue inhibitor of matrix metalloproteinase-3 is down-regulated, while the expression of MMP2 and MMP9 are up-regulated in cardiac muscle (27). There are also a few clinical studies that link vitamin D insufficiency with increased MP production (28-31).

Nowadays, there is evidence that associates vitamin D deficiency with several cardiovascular disorders (Figure 1). However, a causal relationship has not yet been identified. Studies have demonstrated a link between vitamin D deficiency and progression of atherothrombosis and vascular calcification $(32,33)$. Vitamin D has been found to regulate macrophage maturation and infiltration into the vasculature, subsequently regulating the expression of pro-inflammatory cytokines and adhesion molecules, which are critical components in the progression of atherosclerosis (34). These findings are also in line with observations that vitamin-D deficient patients have increased plaque instability and incidence of myocardial infarction. Interestingly, vitamin D supplementation therapy resulted in improvement of inflammatory biomarkers in patients with heart failure (35).

There have been large-scale studies that support the association of low levels of vitamin $\mathrm{D}$ with both prevalent and incident CVD $(31,36)$. Vitamin D deficiency has also been linked to traditional risk factors for CVD such as dyslipidaemia, hypertension and diabetes mellitus (37). Several studies demonstrated that higher vitamin D concentrations are associated with an improved lipid profiling. However, recent meta-analyses have demonstrated there is little evidence for this beneficial effect $(38,39)$. In addition, cross-sectional studies have also revealed an 
association between vitamin D deficiency and diabetes mellitus (40-42). In prospective studies, a clear link between vitamin D levels and coronary heart disease (CHD) in a dose-response manner has been established (43-45). Furthermore, a meta-analysis of 12 prospective studies confirmed an increased $33 \%$ change for CHD in patients with the lowest quartile of vitamin D levels (46). Metaanalyses of several studies focusing on cerebrovascular disease have revealed similar patterns (47-49). Recently, plasma 25-hydroxyvitamin D was associated with mortality in patients with suspected stable angina pectoris (50).

\section{Conclusion}

Vitamin D is a vitamin/hormone with complex action and through its VDR can exert significant cellular effects on multiple biological systems, including the cardiovascular system. Preliminary findings suggest that it is a critical regulator of several cellular components of the cardiovascular system, affecting cellular function, MMP production and inflammatory responses. Clinical trials are required in order to fully establish a clear relationship between vitamin D level and cardiovascular events. It is possible that in the near future, the vitamin D/VDR system may be a potent therapeutic target not only for CVD, but also potentially for several more inflammatory diseases.

\section{Declaration of Interest}

The Authors declare that they do not have any competing interests in regard to this article.

\section{References}

1 Roth GA, Johnson C, Abajobir A, Abd-Allah F, Abera SF, Abyu $\mathrm{G}$ et al: Global, Regional, and National Burden of Cardiovascular Diseases for 10 Causes, 1990 to 2015. J Am Coll Cardiol 70: 1-25, 2017.

2 Tousoulis D, Psarros C, Demosthenous M, Patel R, Antoniades $\mathrm{C}$ and Stefanadis C: Innate and adaptive inflammation as a therapeutic target in vascular disease: the emerging role of statins. J Am Coll Cardiol 63: 2491-2502, 2014.

3 Rocha VZ and Libby P: Obesity, inflammation, and atherosclerosis. Nat Rev Cardiol 6: 399-409, 2009.

4 Naghavi M, Libby P, Falk E, Casscells SW, Litovsky S, Rumberger J, Badimon JJ, Stefanadis C, Moreno P, Pasterkamp G, Fayad Z, Stone PH, Waxman S, Raggi P, Madjid M, Zarrabi A, Burke A, Yuan C, Fitzgerald PJ, Siscovick DS, de Korte CL, Aikawa M, Juhani Airaksinen KE, Assmann G, Becker CR, Chesebro JH, Farb A, Galis ZS, Jackson C, Jang IK, Koenig W, Lodder RA, March K, Demirovic J, Navab M, Priori SG, Rekhter MD, Bahr R, Grundy SM, Mehran R, Colombo A, Boerwinkle E, Ballantyne C, Insull W Jr, Schwartz RS, Vogel R, Serruys PW, Hansson GK, Faxon DP, Kaul S, Drexler H, Greenland P, Muller JE, Virmani R, Ridker PM, Zipes DP, Shah PK and Willerson JT: From vulnerable plaque to vulnerable patient: a call for new definitions and risk assessment strategies: Part II. Circulation 108: 1772-1778, 2003.

5 Singh V, Martinezclark P, Pascual M, Shaw ES and O'Neill WW: Cardiac biomarkers - the old and the new: a review. Coron Artery Dis 21: 244-256, 2010.

6 Vasan RS: Biomarkers of cardiovascular disease: molecular basis and practical considerations. Circulation 113: 2335-2362, 2006.

7 Holick MF: High prevalence of vitamin D inadequacy and implications for health. Mayo Clin Proc 81: 353-373, 2006.

8 Wolf G: The discovery of vitamin D: the contribution of Adolf Windaus. J Nutr 134: 1299-1302, 2004.

9 Holick MF: Vitamin D deficiency. N Eng1 J Med 357: 266-281, 2007.

10 Cashman KD and Kiely M: EURRECA-Estimating vitamin D requirements for deriving dietary reference values. Crit Rev Food Sci Nutr 53: 1097-1109, 2013.

11 Richart T, Li Y and Staessen JA: Renal versus extrarenal activation of vitamin D in relation to atherosclerosis, arterial stiffening, and hypertension. Am J Hypertens 20: 1007-1015, 2007.

12 Zerwekh JE: Blood biomarkers of vitamin D status. Am J Clin Nutr 87: 1087S-1091S, 2008.

13 Prietl B, Treiber G, Pieber TR and Amrein K: Vitamin D and immune function. Nutrients 5: 2502-2521, 2013.

14 Lamberg-Allardt C, Brustad M, Meyer HE and Steingrimsdottir L: Vitamin D - a systematic literature review for the 5th edition of the Nordic Nutrition Recommendations. Food Nutr Res 2013: 57, 2013. doi: 10.3402/fnr.v57i0.22671

15 Stivelman E and Retnakaran R: Role of vitamin D in the pathophysiology and treatment of type 2 diabetes. Curr Diabetes Rev 8: 42-47, 2012.

16 Pike JW and Meyer MB: The vitamin D receptor: new paradigms for the regulation of gene expression by 1,25 dihydroxyvitamin D(3). Endocrinol Metab Clin North Am 39: 255-269, 2010.

17 Ellison TI, Dowd DR and MacDonald PN: Calmodulindependent kinase IV stimulates vitamin D receptor-mediated transcription. Mol Endocrinol 19: 2309-2319, 2005.

18 Chen S, Law CS, Grigsby CL, Olsen K, Hong TT, Zhang Y, Yeghiazarians Y and Gardner DG: Cardiomyocyte-specific deletion of the vitamin $\mathrm{D}$ receptor gene results in cardiac hypertrophy. Circulation 124: 1838-1847, 2011.

19 Merke J, Milde P, Lewicka S, Hugel U, Klaus G, Mangelsdorf DJ, Haussler MR, Rauterberg EW and Ritz E: Identification and regulation of 1,25-dihydroxyvitamin $\mathrm{D}_{3}$ receptor activity and biosynthesis of 1,25-dihydroxyvitamin $\mathrm{D}_{3}$. Studies in cultured bovine aortic endothelial cells and human dermal capillaries. J Clin Invest 83: 1903-1915, 1989.

20 Raymond MA, Desormeaux A, Labelle A, Soulez M, Soulez G, Langelier Y, Pshezhetsky AV and Hebert MJ: Endothelial stress induces the release of vitamin D-binding protein, a novel growth factor. Biochem Biophys Res Commun 338: 1374-1382, 2005.

21 Martinesi M, Bruni S, Stio M and Treves C: 1,25-Dihydroxyvitamin $\mathrm{D}_{3}$ inhibits tumor necrosis factor-alpha-induced adhesion molecule expression in endothelial cells. Cell Biol Int 30: 365-375, 2006.

22 O'Connell TD, Berry JE, Jarvis AK, Somerman MJ and Simpson RU: 1,25-Dihydroxyvitamin $\mathrm{D}_{3}$ regulation of cardiac myocyte proliferation and hypertrophy. Am J Physiol 272: H1751-H1758, 1997. 
23 Simpson RU: Selective knockout of the vitamin D receptor in the heart results in cardiac hypertrophy: is the heart a drugable target for vitamin D receptor agonists? Circulation 124: 1808$1810,2011$.

24 Weishaar RE, Kim SN, Saunders DE and Simpson RU: Involvement of vitamin $\mathrm{D}_{3}$ with cardiovascular function. III. Effects on physical and morphological properties. Am J Physiol 258: E134-E142, 1990.

25 Deng GG, Martin-McNulty B, Sukovich DA, Freay A, HalksMiller M, Thinnes T, Loskutoff DJ, Carmeliet P, Dole WP and Wang YX: Urokinase-type plasminogen activator plays a critical role in angiotensin II-induced abdominal aortic aneurysm. Circ Res 92: 510-517, 2003.

26 Freestone T, Turner RJ, Coady A, Higman DJ, Greenhalgh RM and Powell JT: Inflammation and matrix metalloproteinases in the enlarging abdominal aortic aneurysm. Arterioscler Thromb Vasc Biol 15: 1145-1151, 1995.

27 Boonstra A, Barrat FJ, Crain C, Heath VL, Savelkoul HF and O'Garra A: 1alpha,25-Dihydroxyvitamin d3 has a direct effect on naive CD4(+) $\mathrm{T}$ cells to enhance the development of Th2 cells. J Immunol 167: 4974-4980, 2001.

28 Li YY, Feldman AM, Sun Y and McTiernan CF: Differential expression of tissue inhibitors of metalloproteinases in the failing human heart. Circulation 98: 1728-1734, 1998.

29 Lopez-Lopez N, Gonzalez-Curiel I, Trevino-Santa Cruz MB, Rivas-Santiago B, Trujillo-Paez V, Enciso-Moreno JA and Serrano CJ: Expression and vitamin D-mediated regulation of matrix metalloproteinases (MMPs) and tissue inhibitors of metalloproteinases (TIMPs) in healthy skin and in diabetic foot ulcers. Arch Dermatol Res 306: 809-821, 2014.

30 Timms PM, Mannan N, Hitman GA, Noonan K, Mills PG, Syndercombe-Court D, Aganna E, Price CP and Boucher BJ: Circulating MMP9, vitamin D and variation in the TIMP-1 response with VDR genotype: mechanisms for inflammatory damage in chronic disorders? QJM 95: 787-796, 2002.

31 Wang TJ, Pencina MJ, Booth SL, Jacques PF, Ingelsson E, Lanier K, Benjamin EJ, D'Agostino RB Wolf M and Vasan RS: Vitamin D deficiency and risk of cardiovascular disease. Circulation 117: 503-511, 2008

32 Razzaque MS: The dualistic role of vitamin D in vascular calcifications. Kidney Int 79: 708-714, 2011.

33 Zittermann A, Schleithoff SS and Koerfer R: Vitamin D and vascular calcification. Curr Opin Lipidol 18: 41-46, 2007.

34 Kassi E, Adamopoulos C, Basdra EK and Papavassiliou AG: Role of vitamin D in atherosclerosis. Circulation 128: 25172531,2013

35 Manolagas SC, Provvedini DM, Murray EJ, Tsoukas CD and Deftos LJ: The antiproliferative effect of calcitriol on human peripheral blood mononuclear cells. J Clin Endocrinol Metab 63: 394-400, 1986.

36 Pradhan AD and Manson JE: Update on the Vitamin D and OmegA-3 trial (VITAL). J Steroid Biochem Mol Biol 155: 252256, 2016

37 Norman PE and Powell JT: Vitamin D and cardiovascular disease. Circ Res 114: 379-393, 2014.

38 Karhapaa P, Pihlajamaki J, Porsti I, Kastarinen M, Mustonen J, Niemela $\mathrm{O}$ and Kuusisto $\mathrm{J}$ : Diverse associations of 25hydroxyvitamin $\mathrm{D}$ and 1,25-dihydroxy-vitamin $\mathrm{D}$ with dyslipidaemias. J Intern Med 268: 604-610, 2010.
39 Wang H, Xia N, Yang Y and Peng DQ: Influence of vitamin D supplementation on plasma lipid profiles: a meta-analysis of randomized controlled trials. Lipids Health Dis 11: 42, 2012.

40 Martins D, Wolf M, Pan D, Zadshir A, Tareen N, Thadhani R, Felsenfeld A, Levine B, Mehrotra R and Norris K: Prevalence of cardiovascular risk factors and the serum levels of 25hydroxyvitamin D in the United States: data from the Third National Health and Nutrition Examination Survey. Arch Intern Med 167: 1159-1165, 2007.

41 Oosterwerff MM, Eekhoff EM, Heymans MW, Lips P and van Schoor NM: Serum 25-hydroxyvitamin D levels and the metabolic syndrome in older persons: a population-based study. Clin Endocrinol 75: 608-613, 2011.

42 Pittas AG, Dawson-Hughes B, Li T, Van Dam RM, Willett WC, Manson JE and Hu FB: Vitamin D and calcium intake in relation to type 2 diabetes in women. Diabetes care 29: 650-656, 2006.

43 Giovannucci E, Liu Y, Hollis BW and Rimm EB: 25hydroxyvitamin D and risk of myocardial infarction in men: a prospective study. Arch Intern Med 168: 1174-1180, 2008.

44 Kim DH, Sabour S, Sagar UN, Adams S and Whellan DJ: Prevalence of hypovitaminosis D in cardiovascular diseases (from the National Health and Nutrition Examination Survey 2001 to 2004). Am J Cardiol 102: 1540-1544, 2008.

45 Schottker B, Jorde R, Peasey A, Thorand B, Jansen EH, Groot L, Streppel M, Gardiner J, Ordóñez-Mena JM, Perna L, Wilsgaard T, Rathmann W, Feskens E, Kampman E, Siganos G, Njølstad I, Mathiesen EB, Kubínová R, Pająk A, Topor-Madry R, Tamosiunas A, Hughes M, Kee F, Bobak M, Trichopoulou A, Boffetta P, Brenner H and Consortium on Health and Ageing: Network of Cohorts in Europe and the United States: Vitamin D and mortality: meta-analysis of individual participant data from a large consortium of cohort studies from Europe and the United States. BMJ 348: g3656, 2014.

46 Brondum-Jacobsen P, Benn M, Jensen GB and Nordestgaard BG: 25-hydroxyvitamin d levels and risk of ischemic heart disease, myocardial infarction, and early death: population-based study and meta-analyses of 18 and 17 studies. Arterioscler Thromb Vasc Biol 32: 2794-2802, 2012.

47 Brondum-Jacobsen P, Nordestgaard BG, Schnohr P and Benn M: 25-hydroxyvitamin D and symptomatic ischemic stroke: an original study and meta-analysis. Ann Neurol 73: 38-47, 2013.

48 Bolland MJ, Grey A, Avenell A, Gamble GD and Reid IR: Calcium supplements with or without vitamin D and risk of cardiovascular events: reanalysis of the Women's Health Initiative limited access dataset and meta-analysis. BMJ 342: d2040, 2011.

49 Parker J, Hashmi O, Dutton D, Mavrodaris A, Stranges S, Kandala NB, Clarke A and Franco OH: Levels of vitamin D and cardiometabolic disorders: systematic review and meta-analysis. Maturitas 65: 225-236, 2010.

50 Degerud E, Nygard O, de Vogel S, Hoff R, Svingen GFT, Pedersen ER, Nilsen DWT, Nordrehaug JE, Midttun O, Ueland PM and Dierkes J: Plasma 25-Hydroxyvitamin D and Mortality in Patients With Suspected Stable Angina Pectoris. J Clin Endocrinol Metab 103: 1161-1170, 2018.

Received May 2, 2018

Revised June 12, 2018

Accepted June 18, 2018 